\title{
Zone zero thoracic endovascular aortic repair: A proposed modification to the classification of landing zones
}

\author{
Eric E. Roselli, MD, ${ }^{\mathrm{a}, \mathrm{b}}$ Jay J. Idrees, MD, MPH, ${ }^{\mathrm{a}, \mathrm{b}}$ Douglas R. Johnston, MD, ${ }^{\mathrm{a}, \mathrm{b}}$ \\ Matthew J. Eagleton, MD, ${ }^{\mathrm{a}, \mathrm{c}}$ Milind Y. Desai, MD, ${ }^{\mathrm{a}, \mathrm{d}}$ and Lars G. Svensson, MD, $\mathrm{PhD}^{\mathrm{a}, \mathrm{b}}$
}

\section{ABSTRACT}

Objective: Endovascular stent-grafting provides an alternative treatment option for high-risk patients with ascending aortic disease. The feasibility of this approach has been demonstrated before. We assess the updated experience with ascending thoracic endovascular aortic repair and propose a modification of the landing zone classification based on the outcomes.

Methods: From 2006 to 2016, 39 patients deemed very high risk for open replacement underwent endovascular repair of ascending aorta for acute type A dissection $(12,31 \%)$, intramural hematoma $(2,5 \%)$, pseudoaneurysm $(22,56 \%)$, and chronic dissection suture line entry tear (3,8\%). Ascending thoracic endovascular aortic repair was performed in 36 patients. In 3 patients with pseudoaneurysm, occluder devices were used. Computed tomography imaging analysis was performed, and the extent of aortic pathology was designated by segmental proximity to the left ventricle. Segmental anatomy of the proximal aorta was designed as zone $0 \mathrm{~A}$ from the annulus to the distal margin of highest coronary, $\mathrm{OB}$ extends from above the coronary to the distal margin of right pulmonary artery, and $0 \mathrm{C}$ extends from the right pulmonary artery border to the innominate artery. Multivariable time to event Cox regression analysis was performed to predict mortality, and long-term survival was estimated using the Kaplan-Meier method.

Results: Operative mortality was $13 \%$; all 5 deaths occurred after emergency ascending thoracic endovascular aortic repair for type A dissection. Other complications included stroke in 4 patients $(10 \%)$, myocardial infarction in 2 patients $(5 \%)$, tracheostomy in 2 patients $(5 \%)$, and dialysis in 2 patients $(5 \%)$. In patients with acute type A dissection, the ascending pathology extended into zone $0 \mathrm{~A}$ in $10(71 \%)$ and $0 \mathrm{~B}$ in $4(29 \%)$. Among those with pseudoaneurysm, the location of the defect was in $0 \mathrm{~B}$ in $11(50 \%), 0 \mathrm{C}$ in $10(45 \%)$, and $0 \mathrm{~A}$ in 1 . Among the patients with chronic dissection, the defect was located in $0 \mathrm{C}$ in all $3(100 \%)$. After multivariable adjustment, Cox regression predicted significantly higher hazard of mortality with disease involving zone $0 \mathrm{~A}$ versus $0 \mathrm{C}(P=.020)$ and older age $(P=.026)$. Kaplan-Meier estimate of survival was also significantly worse in patients with disease extension into 0 A versus OC $(P=.0018)$. At 30 days, 1 year, and 5 years, the overall survival was $81 \%, 74 \%$, and $64 \%$ and freedom from reintervention was $85 \%, 77 \%$, and $68 \%$, respectively.

Conclusions: The modified zone zero classification is useful for characterizing extent of ascending aortic pathology and assessing prognosis. Location of the defect varies by pathology, and the presence of $0 \mathrm{~A}$ disease predicts worse outcomes. Design of endovascular devices should be tailored to the aortic pathology and zone characteristics. (J Thorac Cardiovasc Surg 2018;155:1381-9)

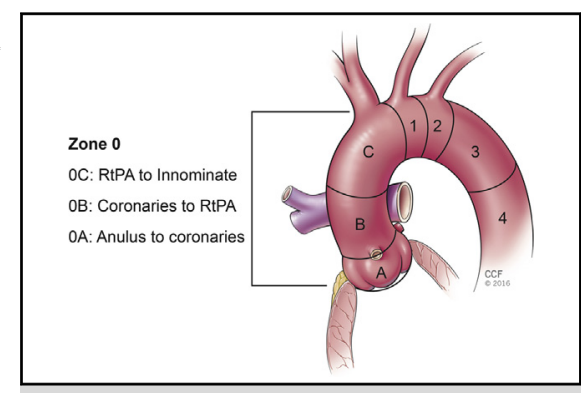

The proposed modification of zone 0 .

Central Message

Zone $0 \mathrm{~A}$ disease has worse prognosis compared with $0 \mathrm{~B}$ or $0 \mathrm{C}$

Perspective

The modified zone zero classification is useful for characterizing the extent of ascending aortic pathology and assessing the prognosis. Location of the defect varies by pathology, and the presence of $0 \mathrm{~A}$ disease predicts worse outcomes. The design of endovascular devices should be tailored to aortic pathology and zone characteristics.

See Editorial Commentary page 1390.

See Editorial page 1358.

\footnotetext{
From the ${ }^{\mathrm{a}}$ Aortic Center, ${ }^{\mathrm{b}}$ Departments of Thoracic and Cardiovascular Surgery, ${ }^{\mathrm{c}}$ Vascular Surgery, and ${ }^{\mathrm{d}}$ Cardiovascular Medicine, Heart and Vascular Institute, Cleveland Clinic, Cleveland, Ohio.

This study was supported in part by the High Risk Cardiovascular Research Fund (to E.E.R.).

Read at the American Association for Thoracic Surgery Aortic Symposium, New York, New York, May 12-13, 2016.
}

Received for publication June 28, 2017; revisions received Oct 19, 2017; accepted for publication Nov 16, 2017; available ahead of print Feb 1, 2018.

Address for reprints: Eric E. Roselli, MD, Department of Thoracic and Cardiovascular Surgery, Cleveland Clinic, 9500 Euclid Ave/Desk J4-1, Cleveland, OH 44195-5108 (E-mail: roselle@ccf.org).

$0022-5223 / \$ 36.00$

Copyright (c) 2017 by The American Association for Thoracic Surgery

https://doi.org/10.1016/j.jtcvs.2017.11.054 


\section{Abbreviations and Acronyms}

$\mathrm{IMH}=$ intramural hematoma

TEVAR $=$ thoracic endovascular aortic repair

Scanning this $Q R$ code will take you to a supplemental video for this article.

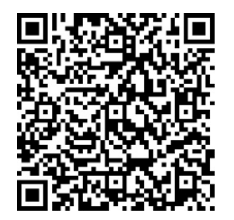

The conventional treatment of proximal aortic aneurysm or dissection is open repair, but some patients are too high risk for this approach and may benefit from a less-invasive alternative with thoracic endovascular aortic repair (TEVAR). ${ }^{1}$ Several studies have reported the feasibility and safety of stent-grafting as a purely endovascular procedure or as part of a hybrid approach for treating ascending and arch aortic pathology, but details about patient selection and long-term outcomes are less well known. ${ }^{1-3}$ Currently, there are no commercially available endovascular devices specifically designed to treat the ascending aorta, and only a small number of studies have described outcomes with the endovascular approach to ascending aortic disease with commercially available devices used offlabel or with early-generation investigational devices. ${ }^{4-7}$

Compared with TEVAR of the descending thoracic aorta, endovascular therapy for the ascending aorta is challenged by more complex pathology, volatile hemodynamics, and variable anatomy within a concentrated anatomic space. However, this entire proximal anatomic segment is currently rather vaguely referred to as "zone zero." ${ }^{8}$ Several device manufacturers are actively pursuing research and development of ascending stent-graft systems. ${ }^{9}$ With the prominence of transcatheter aortic valve replacement, the prospect of combining the 2 technologies is also a realistic consideration. ${ }^{10}$

We recently published our experience with endovascular procedures to treat disease involving the ascending aorta in 22 high-risk patients, and several others have described small experiences. ${ }^{1}$ To date, 39 patients have been treated with this approach. In this article, the outcomes from this experience are updated, and a modification to the landing zone classification is proposed on the basis of this analysis (Figure 1).

\section{PATIENTS AND METHODS \\ Updated Experience With Ascending Stent-Grafting}

From 2006 to November 2016, 39 patients underwent endovascular supracoronary ascending aortic repair at Cleveland Clinic. Presentation and indications for repair included acute type A dissection $(\mathrm{n}=12$, $31 \%)$, acute intramural hematoma (IMH) $(\mathrm{n}=2,5 \%)$, pseudoaneurysm $(\mathrm{n}=22,56 \%)$, and chronic dissection with false lumen perfusion from a

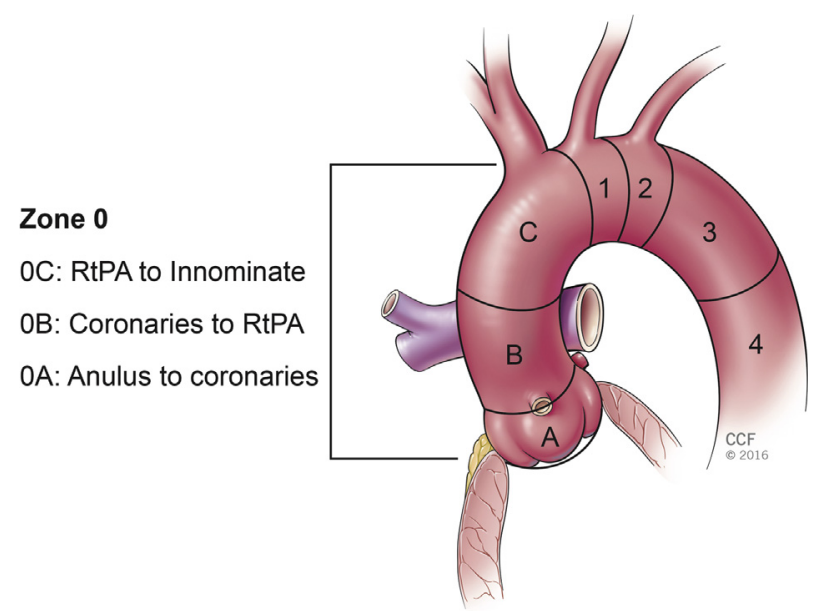

FIGURE 1. Proposed modification of zone zero. RtPA, Right pulmonary artery.

distal suture line entry tear after ascending aortic replacement $(n=3$, $8 \%$ ). All patients were considered high risk for conventional open repair at the time of presentation. The Cleveland Clinic Institutional Review Board approved the study with patient consent waived. Table 1 outlines the distribution of comorbidities according to underlying aortic pathology at presentation. Of note, the underlying comorbidities were similar in the 3 groups, except that coronary artery disease $(P=.014)$ and history of cardiac surgery $(P<.001)$ were significantly higher in patients with pseudoaneurysm.

\section{Operative Details and Technique}

Stent-grafts were used in 36 patients $(95 \%)$, atrial septal occluder devices were used in 2 patients, and coil embolization was used in 1 patient. Of the 2 patients in whom an atrial septal occluder device was used to close the defect, 1 presented with pseudoaneurysm after previous aortic root replacement and a fistula from the posterior wall of the mid-aorta to the right main pulmonary artery. The presence of a small mechanical aortic valve prevented crossing with a stent-graft device. Both pulmonary artery and aortic defects were plugged with septal closure devices and the aortic one was reinforced by a balloon-expandable stent in the ascending aorta. In the other patient, the pseudoaneurysm origin was in close vicinity to both a critically important coronary bypass graft and the brachiocephalic artery without enough room for the commercially available stent-grafts. In 1 patient an endovascular occlusion of a pseudoaneurysm was attempted by embolization, but was not successful and an open repair was performed instead.

All procedures were done under general anesthesia with heparin for anticoagulation. Device delivery was transfemoral $(\mathrm{n}=22,56 \%)$, transapical $(n=8,22 \%)$, or through the axillary artery $(n=9,23 \%)$. Transfemoral delivery was performed over a stiff wire with access across the aortic valve (Video 1). Transapical delivery used through-and-through wire access to the left subclavian artery, and axillary delivery was performed through a 10-mm surgical graft. In 2 patients, the device was deployed on full cardiopulmonary bypass. One of these had a left ventricular ejection fraction of $10 \%$, and the other had severe right heart failure with wide open tricuspid regurgitation that was repaired surgically simultaneously through a full sternotomy on the beating heart and the ascending pseudoaneurysm was stented via transfemoral access. In all others, rapid ventricular pacing during deployment reduced displacement forces. Transesophageal echocardiography and fluoroscopy guided positioning. Completion angiogram was performed to assess 
TABLE 1. Patient comorbidities according to aortic pathology

\begin{tabular}{|c|c|c|c|c|}
\hline & $\frac{\text { Pseudoaneurysm }}{n=22(56)}$ & $\frac{\text { Type A/IMH }}{\mathrm{n}=14(36)}$ & $\frac{\text { Chronic dissection }}{\mathbf{n}=\mathbf{3}(\mathbf{8})}$ & $P$ value \\
\hline Age, y, median (IQR) & $67.5(61-77)$ & $80(74-84)$ & $71(64-75)$ & .084 \\
\hline Maximum aortic diameter, median (IQR) & $63.65(46-74)$ & $57.95(43-64.5)$ & $57.7(52-63.4)$ & .65 \\
\hline Ejection fraction, median (IQR) & $55(43-56)$ & $55(55-60)$ & $55(15-63)$ & .66 \\
\hline Male & $17(77)$ & $4(29)$ & $2(67)$ & .011 \\
\hline Prior cardiac surgery & $22(100)$ & $5(36)$ & $3(100)$ & $<.001$ \\
\hline Hypertension & $19(90)$ & $13(93)$ & $3(100)$ & $>.9$ \\
\hline Prior stroke & $3(14)$ & $4(29)$ & 0 & .44 \\
\hline Diabetes & $3(14)$ & $5(36)$ & 0 & .3 \\
\hline COPD & $3(14)$ & $4(29)$ & $1(33)$ & .38 \\
\hline Chronic renal failure & $6(29)$ & $2(14)$ & 0 & .48 \\
\hline Coronary arterial disease & $15(71)$ & $5(36)$ & 0 & .014 \\
\hline Prior myocardial infarction & $3(14)$ & $4(29)$ & 0 & .44 \\
\hline Cancer & $3(14)$ & $2(14)$ & $2(67)$ & .12 \\
\hline Aortic insufficiency & $3(14)$ & $6(43)$ & $1(33)$ & .12 \\
\hline Congestive cardiac failure & $7(50)$ & $4(29)$ & $1(33)$ & .66 \\
\hline$>1$ comorbidity & $15(71)$ & $12(86)$ & $2(67)$ & .51 \\
\hline \multicolumn{5}{|l|}{ No. of comorbidities } \\
\hline 1 & $2(9)$ & $3(21)$ & $1(33)$ & .93 \\
\hline 2 & $5(23)$ & $3(21)$ & $1(33)$ & \\
\hline 3 & $6(27)$ & $3(21)$ & $1(33)$ & \\
\hline 4 & $2(9)$ & $1(7)$ & 0 & \\
\hline 5 & $4(18)$ & $4(29)$ & 0 & \\
\hline 6 & $1(5)$ & 0 & 0 & \\
\hline In-hospital mortality & 0 & $5(36)$ & 0 & .006 \\
\hline Stroke & $2(8.3)$ & $2(14)$ & 0 & .65 \\
\hline Dialysis & 0 & $1(7)$ & 0 & .45 \\
\hline Tracheostomy & 0 & $2(14)$ & 0 & .28 \\
\hline Late death & $4(18)$ & $4(29)$ & 0 & .71 \\
\hline
\end{tabular}

$I M H$, Intramural hematoma; $I Q R$, interquartile range; $C O P D$, chronic obstructive pulmonary disease.

coronary and arch vessel patency, and to rule out endoleak. All patients were transferred from the hybrid operating room to the intensive care unit.

More than 1 stent-graft device was used in 18 patients $(50 \%)$. The ascending aorta was anatomically divided into 3 segments to describe the proximal-most extent of disease and device positioning. Results of this classification are shown in Table 2.

\section{Definitions, Follow-up, and Statistics}

Operative mortality is defined as death occurring within 30 days of the procedure or during hospitalization. Stroke was defined as neurologic deficit lasting greater than 24 hours confirmed by cross-sectional imaging of the brain or documentation by a neurologist. Renal failure was defined as the need for hemodialysis, and respiratory failure was defined as the need for reintubation or tracheostomy postoperatively. Computed tomography was performed before discharge, during outpatient follow-up at 3 months, and then annually unless otherwise indicated. Median follow-up was 13.4 (1-100) months.

Descriptive statistical analyses are used to present variables for the study. Continuous variables are presented as median or mean \pm standard deviation, and categoric variables are presented as percentages. Time to event analysis was performed using the multivariable Cox proportional hazard regression. Tests for proportional hazard assumption were performed using the scaled Schoenfeld residuals, which indicated that the model assumptions were not violated $(P=.206)$. Long-term survival was estimated using the Kaplan-Meier method, and the log-rank test was used to assess significance.

\section{RESULTS}

\section{Disease Extent According to Zone}

In the first group of patients with acute type A dissection or IMH, the aortic pathology extended proximally to zone $0 \mathrm{~A}$ in $10(71 \%)$ and $0 \mathrm{~B}$ in $4(29 \%)$. All patients in the group who were treated for pseudoaneurysm had a previous cardiac operation, and 59\% had a surgical graft from previous ascending aortic replacement. The location of the defect in these patients was at $0 \mathrm{~B}$ in 11 patients 


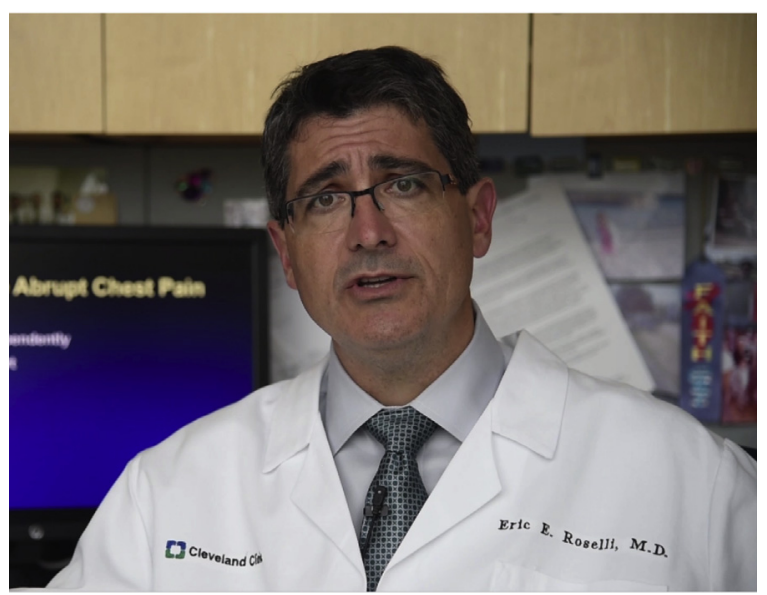

VIDEO 1. Ascending stent-grafting in high-risk patients. Video available at: http://www.jtcvsonline.org/article/S0022-5223(17)32741-1/fulltext.

$(50 \%)$ and more distally $0 \mathrm{C}$ in 10 patients $(45 \%)$. In 1 patient, although the defect was more distal, the pseudoaneurysm was large and extended proximally as far as zone $0 \mathrm{~A}$. In the third group of patients with chronic dissection and persistent proximal flow into the false lumen, the defect was located at the distal suture line in $0 \mathrm{C}$ in all 3 patients.

\section{Proximal Landing Zone Location of Thoracic Endovascular Aortic Repair in Zone 0}

In 4 patients, the proximal landing zone for TEVAR partially extended into $0 \mathrm{~A}$; in 3 of these patients the indication was acute type A dissection and 1 patient had IMH. These included 1 with partial coverage of the left main coronary requiring open conversion and 1 who had a previous transcatheter aortic valve in place. In all remaining cases of acute type A dissection, pseudoaneurysm, and chronic dissection, the proximal landing zone for TEVAR

TABLE 2. Predictors of mortality

\begin{tabular}{lcc}
\hline & HR \pm SE & $P$ value \\
\hline Age & $1.09 \pm 0.04$ & .026 \\
Gender & $1.08 \pm 1.37$ & .951 \\
\hline Acute type A dissection & $1.87 \pm 2.20$ & .590 \\
Pathology: zone 0A vs 0C & $30.76 \pm 45.15$ & .020 \\
\hline Pathology: zone 0B vs 0C & $9.9 \pm 9.90$ & .132 \\
Proximal landing zone 0A vs & $0.22 \pm 0.32$ & .291 \\
$\quad$ 0B & & \\
Diabetes & $7.13 \pm 8.07$ & .082 \\
Hypertension & $0.792 \pm 0.97$ & .849 \\
Chronic renal failure & $6.24 \pm 7.83$ & .145 \\
Aortic insufficiency & $0.733 \pm 0.64$ & .723 \\
COPD & $0.875 \pm 0.88$ & .894 \\
Multiple comorbidities & $0.687 \pm 0.30$ & .385 \\
\hline
\end{tabular}

$H R$, Hazard ratio; $S E$, standard error; $C O P D$, chronic obstructive pulmonary disease. was in zone $0 \mathrm{~B}$. The distal landing zone was $0 \mathrm{C}$ in most patents except for 1 who underwent additional stent-grafting of the arch and descending aorta with a branched device (Figure 2).

\section{Predictors of Mortality}

After adjusting for baseline patient characteristics, surgical indication, and comorbidities, multivariable time to event analysis using Cox regression model showed that older age $(P=.026)$ and aortic pathology extending into zone 0A $(P=.020)$ were independent predictors of mortality (Table 2). The presence of acute type A dissection $(P=.59)$ and proximity of landing zone $(P=.291)$ were not significantly associated with overall death. Table 3 provides the summary of aortic pathology by zone in patients who died.

\section{Early Events}

Four patients (10\%) required early conversion to open repair: 1 for a retained delivery system, 1 for left main coronary occlusion, 1 for acute aortic insufficiency due to displacement of a mechanical valve leaflet, and 1 for whom embolization of the pseudoaneurysm was not successful. Of the 4 patients who underwent early conversion to open repair, 3 are still alive during late follow-up. There were $5(13 \%)$ hospital deaths; 1 was intraoperative. All 5 patients underwent emergency repair of acute type A dissection. One refused blood transfusions for religious reasons and died on postoperative day 4 due to rupture and tamponade. Another had dissected a chronic ascending aneurysm that eroded into the left atrium, and he bled from the left atrium after ascending stent-grafting resulted in tamponade and intraoperative death. Two patients died of multiorgan failure postoperatively, including 1 with partial occlusion of the left coronary artery that required conversion to open repair. The other patient had progressive cardiopulmonary collapse and died of cardiac arrest on postoperative day 5. The patient who required open conversion for a retained delivery system tolerated the repair, but required later reoperation for an apical pseudoaneurysm. This patient is still alive and doing well 5 years later. The other patient who required conversion for acute aortic insufficiency also tolerated the redo root and ascending and arch repair but required a right leg fasciotomy for compartment syndrome.

Four patients (10\%) had stroke ( 1 delayed by 2 weeks), 2 patients $(5 \%)$ had myocardial infarction, 2 patients $(5 \%)$ required tracheostomy for respiratory failure, and 2 patients $(5 \%)$ developed renal failure requiring dialysis.

\section{Long-term Survival}

Overall, the estimated survival at 30 days, 1 year, and 5 years was $81 \%, 74 \%$, and $64 \%$, respectively (Figure 3). Among patients who underwent ascending 

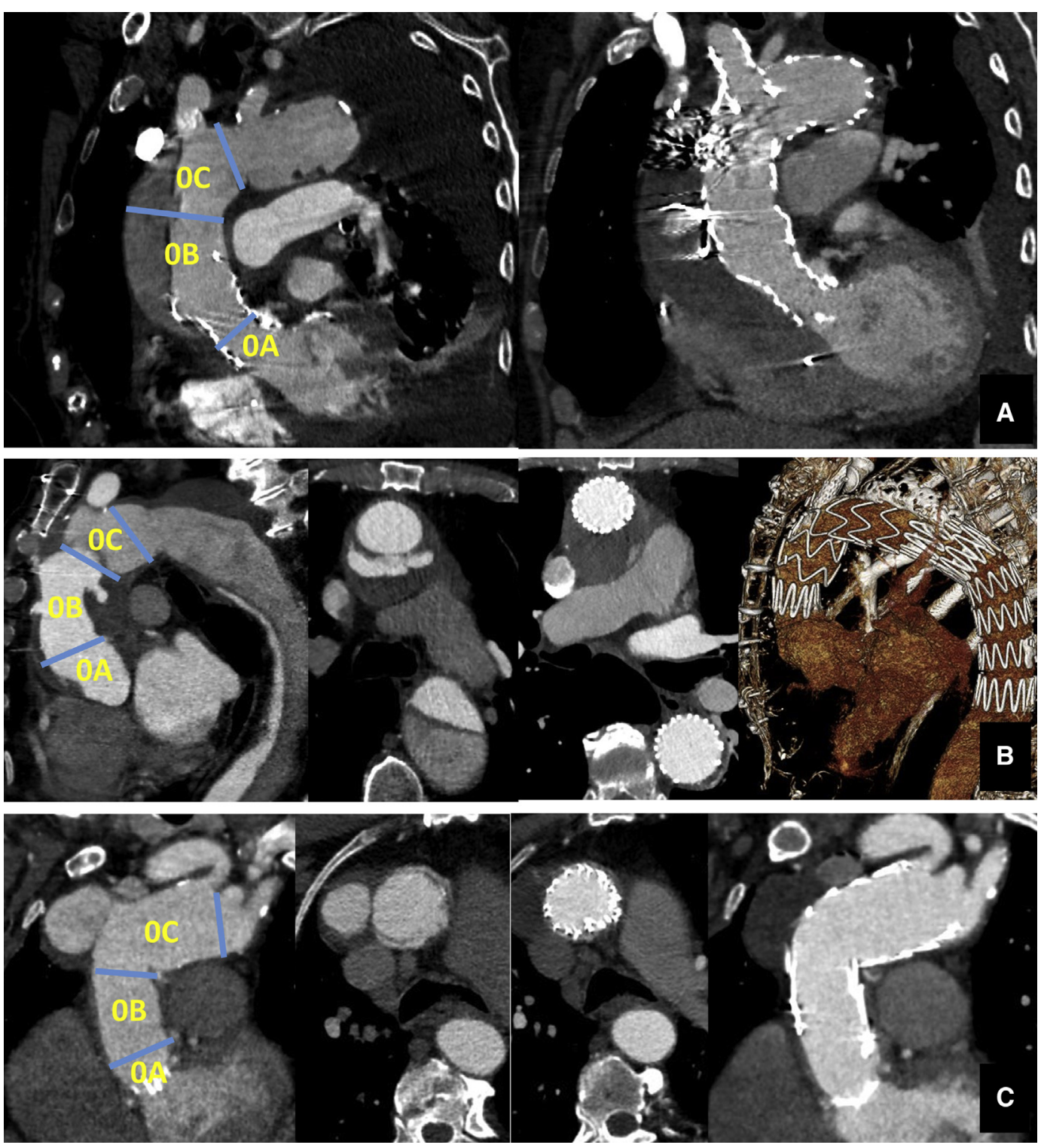

FIGURE 2. Characterization of ascending pathology according to zone 0 subclassification. A, Acute dissection in a patient with previous TAVR showing extension into zone 0A. B, Chronic dissection with distal suture line entry tear after previous Ascending repair. The defect is located in zone 0B. C, Saccular aneurysm located in zone $0 \mathrm{C}$.

TEVAR for pseudoaneurysm, the survival at 30 days, 1 year, and 5 years was $100 \%, 90 \%$, and $68 \%$, respectively, versus in patients with acute type A dissection/IMH, in whom the survival was $57 \%, 41 \%$, and $41 \%$, respectively $(P=.0057)$. Survival in patients with zone 0A pathology was significantly worse compared with those with $0 \mathrm{~B}$ or 0C disease. At 30 days, 1 year, and 5 years, the survival was $55 \%, 33 \%$, and $33 \%$ in patients with $0 \mathrm{~A}$ disease versus $92 \%, 88 \%$, and $75 \%$, respectively, in patients with $0 \mathrm{~B}$ or 0C disease $(P=.0018)$. There were 8 late deaths: 1 from lung cancer, 1 from pneumonia, and 1 from rupture of an intracranial aneurysm. One patient was a 91-year-old who had a stroke and was discharged to a nursing facility, where he died. The exact cause is unknown in 4 patients.

\section{Late Reinterventions}

One patient had distal migration of the stent-graft into the arch found incidentally during 6-month follow-up computed tomography. He had no symptoms, and the pseudoaneurysm completely resolved. At the time of endovascular repair, the patient was acutely ill but had since recovered, and the migrated device was extracted electively via an open approach. The other late reoperation was for a ventricular apex pseudoaneurysm caused by wire perforation.

In 2 other patients, open reoperations were planned as part of a staged approach. Emergency TEVAR was performed first in both patients who were too sick at presentation but later recovered to become candidates for 
TABLE 3. Aortic pathology and zone zero characteristics of patients who died

\begin{tabular}{|c|c|c|c|c|c|}
\hline Outcome & Disease location & Proximal landing zone & Type A dissection & IMH & Pseudoaneurysm \\
\hline \multicolumn{6}{|l|}{ Operative mortality $(\mathrm{n}=5,13 \%)$} \\
\hline Zone 0A (annulus to coronary) & $5(100 \%)$ & $2(40 \%)$ & $5(100 \%)$ & 0 & 0 \\
\hline Zone 0B (coronary through right PA) & 0 & $3(60 \%)$ & 0 & 0 & 0 \\
\hline Zone 0C (right PA through innominate) & 0 & 0 & 0 & 0 & 0 \\
\hline \multicolumn{6}{|l|}{ Late death $(\mathrm{n}=8,21 \%)$} \\
\hline Zone 0A (annulus to coronary) & $3(38 \%)$ & $1(13 \%)$ & $2(25 \%)$ & $1(13 \%)$ & 0 \\
\hline Zone $0 \mathrm{~B}$ (coronary through right $\mathrm{PA}$ ) & $4(50 \%)$ & $7(88 \%)$ & $1(13 \%)$ & 0 & $3(38 \%)$ \\
\hline Zone 0C (right PA through innominate) & $1(13 \%)$ & 0 & 0 & 0 & $1(13 \%)$ \\
\hline
\end{tabular}

$I M H$, Intramural hematoma; $P A$, pulmonary artery.

open repair. One had acute dissection and rupture 2 months after mitral repair and coronary bypass grafting complicated by myocardial infarction requiring coronary stenting. The rupture was successfully treated by stent-grafting, and the residual dissection and aneurysm were treated 4 months later when clopidogrel could be safely stopped. The other patient presented with hemoptysis, respiratory failure, and cardiogenic shock due to high-output fistula. The fistula was treated

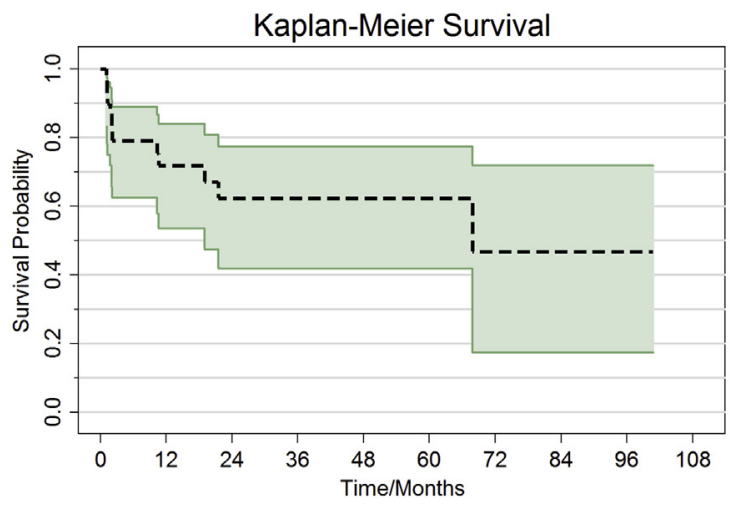

Number at Risk:

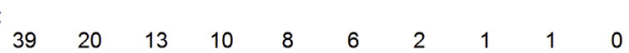

endovascularly, the patient's condition was stabilized, and he was safely taken for redo open repair 6 days later.

\section{Endovascular Reinterventions}

One patient was treated with TEVAR extension for distal type 1 endoleak, and it resolved. Two patients underwent coil embolization of the pseudoaneurysm for endoleak. There were 5 other type 1 endoleaks. One patient had the planned conversion described in the previous paragraph,

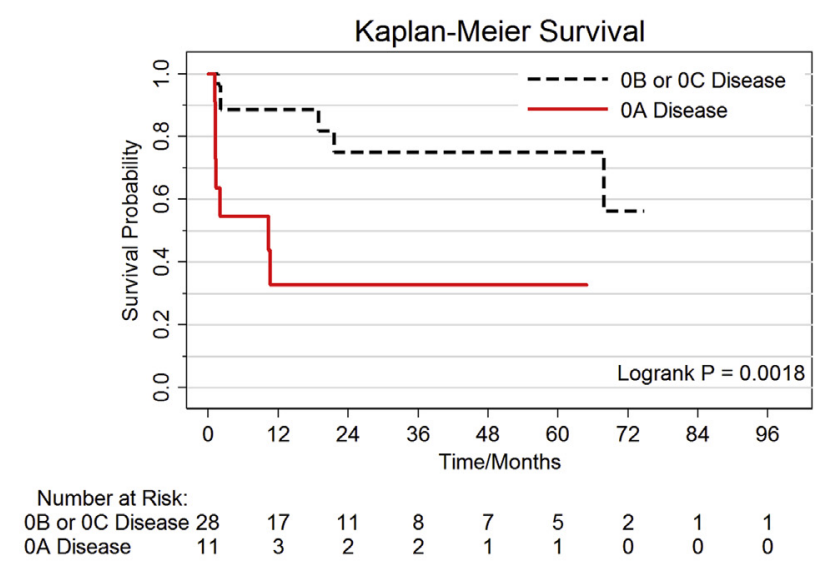

B

A

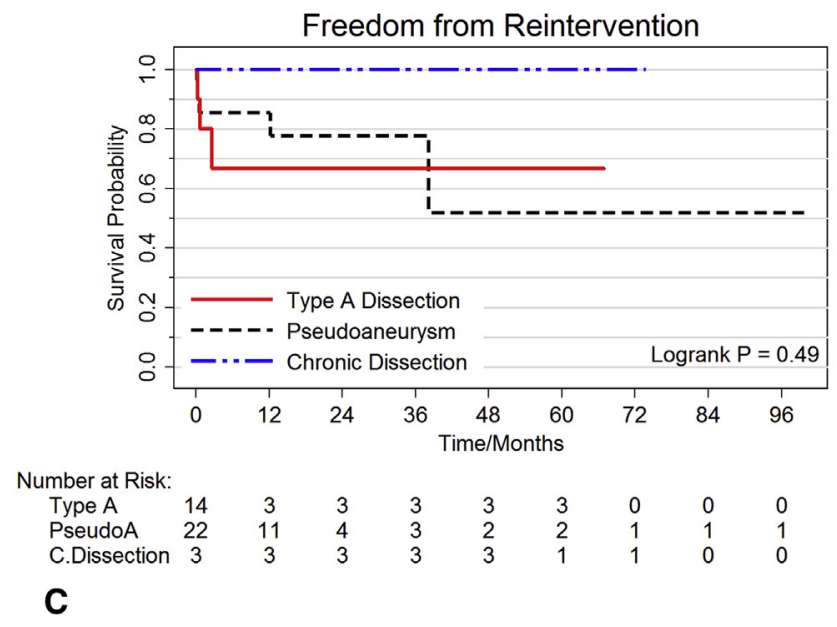

FIGURE 3. A, Survival. B, Overall survival according to zone classification of aortic pathology: $0 \mathrm{~A}$ versus $0 \mathrm{~B}$ or $0 \mathrm{C}$. C, Freedom from reoperation by aortic pathology. 
1 patient without aneurysm resolved slowly over 2 years, 2 patients refused further treatment, and 1 patient is being monitored expectantly.

\section{Freedom From Reintervention}

At 1 month and 1, 3, and 5 years, the freedom from reintervention was $85 \%, 77 \%, 77 \%$, and $68 \%$, respectively. There was no significant difference in groups by indication $(P=.49)$ (Figure $3, C)$. Six $(18 \%)$ of 34 survivors required late reinterventions (4 open, 2 endovascular). One 88-year-old woman and one 85-yearold woman have persistent distal endoleak after stent-grafting for acute type A dissection but refuse any further therapy.

\section{DISCUSSION}

\section{Zone Zero Stent-Grafting for Arch Disease}

Hybrid aortic repair combining open and endovascular techniques can be performed in multiple ways and may be classified by mechanical circulatory support and timing. Much of what has been written about zone zero stent-grafting has involved type 1 or type 2 hybrid operations where the arch vessels are debranched, or transposed, to a more proximal portion of the native ascending aorta (type 1 hybrid arch repair) or an ascending surgical graft (type 2 hybrid arch repair) with subsequent stent-grafting from the ascending aorta segment through the native arch and descending segments. ${ }^{3}$ Results from small single-center series have been reasonable for this approach, but retrograde dissections have been reported to occur in as many as $24 \%$ of patients undergoing type 1 hybrid repair because the ascending aorta is often diseased. ${ }^{10}$ Although placing the stent-graft into a surgical graft can address the problem of retrograde dissection, type 1 endoleaks are too common in both type 1 and type 2 hybrid repairs. Previously placed surgical grafts are often too short to accommodate a debranching source and provide a landing zone for fixation and seal of the stent-graft. A type 3 hybrid repair combining open circulatory arrest and endovascular devices can address the shortcomings presented by both type 1 and type 2 repairs. ${ }^{10,14,15}$ However, all of these hybrid techniques are directed at disease primarily involving the arch and descending aorta.

\section{Zone Zero Stent-Grafting for Ascending Aortic Disease}

For patients with disease predominantly involving the ascending aorta, open surgical replacement has been shown to be safe for the majority of patients, including those requiring reoperations and multi-component operations. ${ }^{11}$ However, there is an underappreciated need to provide alternative therapy for patients considered high risk for open repair. ${ }^{12,13}$
Several centers have used stent-graft devices to treat ascending aortic disease demonstrating feasibility for select patients using both off-label application of commercially available devices and with very early versions of investigational devices. ${ }^{3-7}$ These early experiences have demonstrated some important challenges to ascending aortic endovascular repair that can be categorized as patient related or procedure related.

Patient-related challenges to ascending TEVAR include issues with the specific anatomy and morphology of the ascending aorta. Although we typically use straight tubular grafts to perform ascending replacement, the native segment is different from a straight tube. The posterior wall and lesser curve of the aorta are shorter than the greater curve and anterior walls (Figure 4). In our earlier analysis of computed tomography of patients with an ascending stent-graft, we found that the greater curve is more than $30 \%$ longer than the lesser curve along the length of the ascending aorta. ${ }^{3}$ In a more recent imaging analysis of computed tomography scans from a population of patients deemed inoperable for acute type A dissection, we found a similar difference in length measurements. ${ }^{12}$

The population of patients deemed inoperable for acute type A dissection presents an unmet need. In our experience, $7.7 \%$ of patients with type A dissection were not offered an operation. In the International Registry of Aortic Dissection (IRAD) experience, they found that more than $20 \%$ of patients with type A dissection were deemed inoperable. ${ }^{13}$ A fundamental principle for successful endovascular treatment of these patients is the need to cover the proximal entry tear. Identifying this lesion on preoperative imaging was possible in most patients but still represents an important challenge going forward. For many of these patients, the reasons for inoperability may not be prohibitive if a stent-graft was available as a less morbid mechanical treatment option that allowed us to cover the entire ascending aortic segment.

This experience also introduces the potential role of this technology as an adjunct to definitive repair. We demonstrated in our experience that most patients who required open conversion (3/4 early and 5/6 overall) are late survivors.

The collective experience of ascending stent-grafting has brought to light many of the important details about the procedure and shortcomings of the current technology. Before designing the ideal device, it will be helpful to improve our understanding of the boundary conditions for these devices. Studies are ongoing to better characterize the elasticity and compliance, load testing, and histology of the ascending aorta in the normal, aneurysmal, and acutely dissected states. This knowledge will help to guide the development of better site-specific and disease-specific devices. 

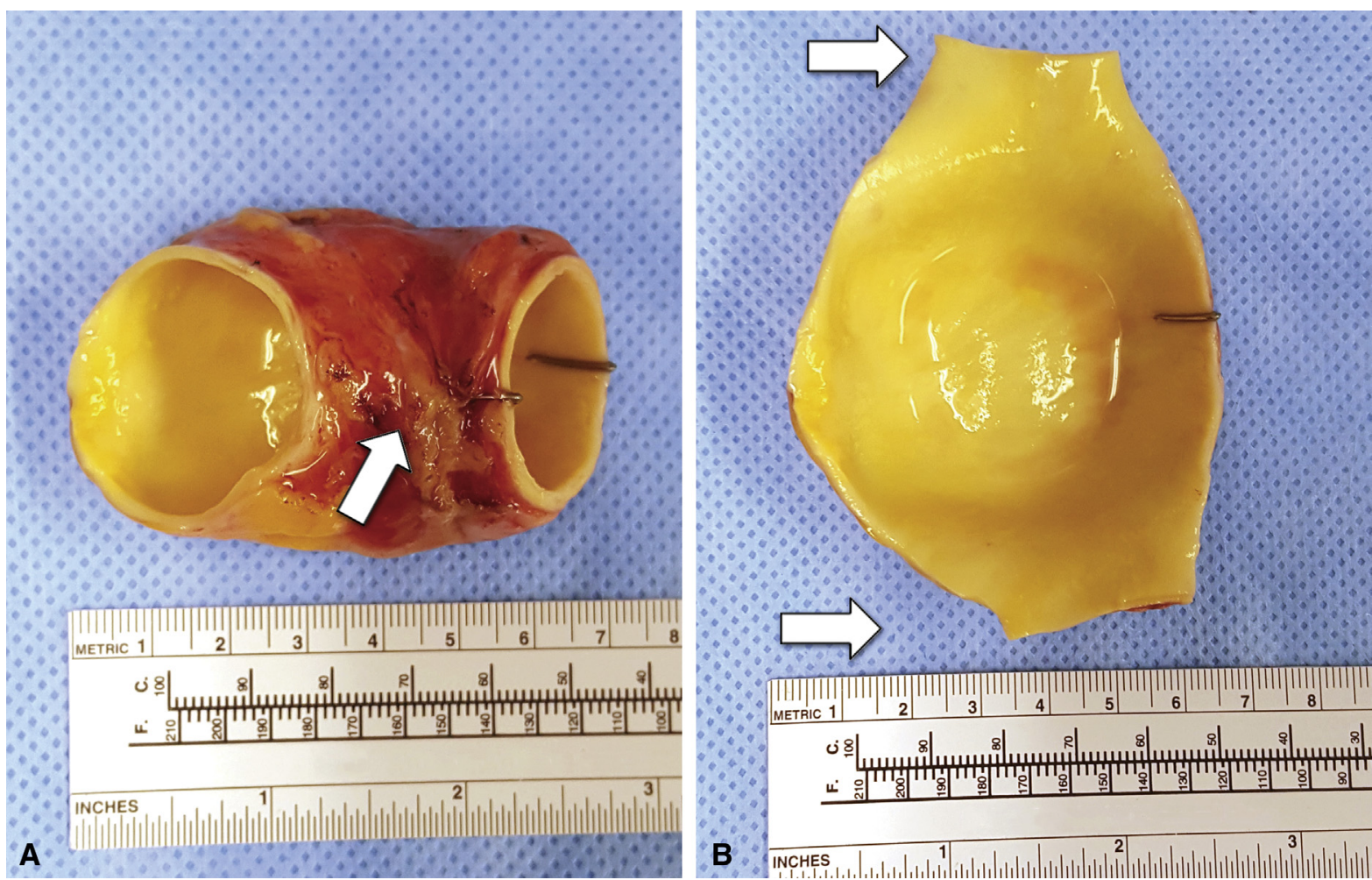

FIGURE 4. Resected native ascending aorta showing shorter posterior wall (white arrow) of intact specimen (A) and lesser curve (white arrow) of the same, opened specimen (B).

The next-generation ascending stent-graft device needs to be highly conformable and elastic with adequate strength of fixation in what is a hostile environment. The device likely needs to be curved like the ascending aorta. It should have a relatively flush edge proximally so that it does not impose on the origins of the coronaries or the commissures of the aortic valve despite the need to abut them. As we learn more about the endovascular treatment of ascending disease, we will better understand the need for branched devices to accommodate the brachiocephalic and other arch branch vessels so that distal seal and fixation are achieved.

The novel delivery systems will need to be exceedingly precise to allow for controlled deployment at the sinotubular junction in a coaxial plane. This may require a repositionable system that is steerable. The tip of the delivery system needs to be short because of the proximity to the aortic valve. The least-invasive delivery options are retrograde, but a system that allows for antegrade delivery from the left ventricular apex may be considered.

\section{Study Limitations}

This is a retrospective analysis. Imaging data were not available in all patients with acute type A dissection. The study population consisted of a heterogeneous mix of patients with diverse presentation and aortic pathology.
Finally, because of a small sample size, the scope of the analysis was limited but still offers important insight into the development of this novel treatment.

\section{Proposed New Classification for Zone Zero}

In the current landing zone classification system, any portion of the aorta proximal to the left common carotid artery is considered zone zero. ${ }^{8}$ In the latest analysis of our experience at the Cleveland Clinic in performing ascending stent-grafting, we have found that there is an important difference in procedural difficulty and early and intermediate outcomes based on a more granular view of the proximal landing zone. In this modified classification system, we further delineated zone zero into 3 segments. Zone 0A constitutes the aortic root and is defined proximally by the left ventricular outflow tract and distally by the distal edge of the coronary ostia. Zone $0 \mathrm{~B}$ constitutes the proximal half of the ascending aorta and is defined as the region between the distal coronary ostia and the right main pulmonary artery, and zone $0 \mathrm{C}$ is the distal half of the ascending aorta extending from the right main pulmonary artery and including the brachiocephalic trunk (Figure 1).

Our analysis of both early and late outcomes based on this more precise modified zone zero classification system validates its use as both a descriptive and prognostic tool. It was not surprising to find that all of the early deaths in 
this experience were in patients with acute dissections, but the risk was particularly high in those with acute dissections involving the root (one third has zone $0 \mathrm{~B}$ disease). The time to event analysis included all deaths, and the multivariable analysis of this outcome demonstrated that extent zone 0A disease independently predicted mortality irrespective of the underlying aortic pathology.

\section{CONCLUSIONS}

Some of these associations could be related to the shortcomings of the current technology that are particularly ill-suited for the proximal most segment of the aorta. As our understanding of the disease and the technology to treat it evolves, we can anticipate having both site- and disease-specific devices for endovascular repair of the proximal aorta. Now is the time to expand the zone-based classification system to better describe the proximal aorta so that we can gather more detailed data to facilitate these advances.

\section{Conflict of Interest Statement}

Dr Roselli receives honoraria for consulting and speaking from Bolton, Gore, Medtronic, and Vascutek. All other authors have nothing to disclose with regard to commercial support.

\section{References}

1. Roselli EE, Idrees J, Greenberg RK, Johnston DR, Lytle BW. Endovascular stent grafting for ascending aorta repair in high-risk patients. J Thorac Cardiovasc Surg. 2015;149:144-51.

2. Czerny M, Weigang E, Sodeck G, Schmidli J, Antona C, Gelpi G, et al. Targeting landing zone 0 by total arch rerouting and TEVAR: midterm results of a transcontinental registry. Ann Thorac Surg. 2012;94:84-9.

3. Bavaria J, Milewski RK, Baker J, Moeller P, Szeto W, Pochettino A. Classic hybrid evolving approach to distal arch aneurysms: toward the zone zero solution. J Thorac Cardiovasc Surg. 2010;140(6 Suppl):S77-80; discussion S86-91.
4. Preventza O, Henry MJ, Cheong BY, Coselli JS. Endovascular repair of the ascending aorta: when and how to implement the current technology. Ann Thorac Surg. 2014;97:1555-60.

5. Lu Q, Feng J, Zhou J, Zhao Z, Bao J, Feng R, et al. Endovascular repair of ascending aortic dissection: a novel treatment option for patients judged unfit for direct surgical repair. J Am Coll Cardiol. 2013;61:1917-24.

6. Li Z, Lu Q, Feng R, Zhou J, Zhao Z, Bao J, et al. Outcomes of endovascular repair of ascending aortic dissection in patients unsuitable for direct surgical repair. J Am Coll Cardiol. 2016;68:1944-54.

7. Khoynezhad A, Donayre CE, Walot I, Koopmann MC, Kopchok GE, White RA. Feasibility of endovascular repair of ascending aortic pathologies as part of an FDA-approved physician-sponsored investigational device exemption. J Vasc Surg. 2016;63:1483-95.

8. Fillinger M, Greenberg R, McKinsey JF, Chaikof EL, Society for Vascular Surgery Ad Hoc Committee on TEVAR Reporting Standards. Reporting standards for thoracic endovascular aortic repair (TEVAR). J Vasc Surg. 2010;52:1022-33.

9. Rylski B, Szeto WY, Bavaria JE, Branchetti E, Moser W, Milewski RK Development of a single endovascular device for aortic valve replacement and ascending aortic repair. J Card Surg. 2014;29:371-6.

10. Andersen ND, Williams JB, Hanna JM, Shah AA, McCann RL, Hughes GC Results with an algorithmic approach to hybrid repair of the aortic arch. $J$ Vasc Surg. 2013;57:655-67.

11. Idrees JJ, Roselli EE, Lowry AM, Reside JM, Javadikasgari H, Johnson DJ, et al Outcomes after elective proximal aortic replacement: a matched comparison of isolated versus multicomponent operations. Ann Thorac Surg. 2016;101: 2185-92.

12. Roselli EE, Hasan SM, Idrees JJ, Aftab M, Eagleton M, Menon V, et al Inoperable patients with acute type A dissection: are they candidates for endovascular repair? Interact Cardiovasc Thorac Surg. 2017; 25:582-8.

13. Trimarchi S, Nienaber CA, Rampoldi V, Myrmel T, Suzuki T, Mehta RH, et al. Contemporary results of surgery in acute type A aortic dissection: The International Registry of Acute Aortic Dissection experience. J Thorac Cardiovasc Surg. 2005;129:112-22.

14. Idrees JJ, Roselli EE, Wojnarski CM, Feng K, Aftab M, Johnston DR, et al. Prophylactic stage 1 elephant trunk for moderately dilated descending aorta in patients with predominantly proximal disease. J Thorac Cardiovasc Surg. 2015;150:1150-5.

15. Lima B, Roselli EE, Soltesz EG, Johnston DR, Pujara AC, Idrees J, et al Modified and "reverse" frozen elephant trunk repairs for extensive disease and complications after stent grafting. Ann Thorac Surg. 2012;93:103-9.

Key Words: ascending aorta, stent grafting, endovascular, thoracic endovascular aortic repair (TEVAR), landing zone 